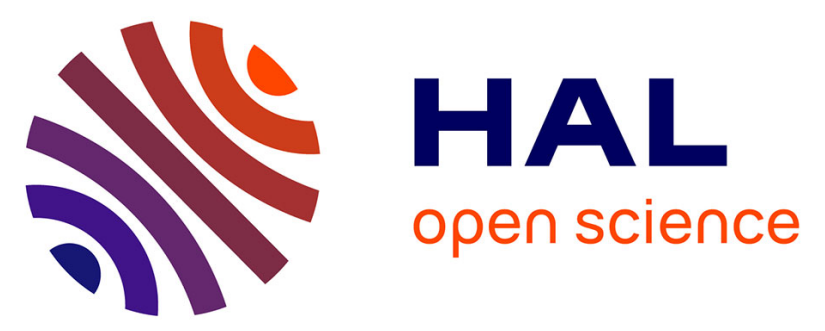

\title{
Age effect on the default mode network, inner thoughts, and cognitive abilities.
}

\author{
Katell Mevel, Brigitte Landeau, Marine Fouquet, Renaud La Joie, Nicolas \\ Villain, Florence Mézenge, Audrey Perrotin, Francis Eustache, Beatrice \\ Desgranges, Gaël Chételat
}

\section{To cite this version:}

Katell Mevel, Brigitte Landeau, Marine Fouquet, Renaud La Joie, Nicolas Villain, et al.. Age effect on the default mode network, inner thoughts, and cognitive abilities.. Neurobiology of Aging, 2013, 34 (4), pp.1292-301. 10.1016/j.neurobiolaging.2012.08.018 . inserm-00729080

\section{HAL Id: inserm-00729080 https://www.hal.inserm.fr/inserm-00729080}

Submitted on 7 Sep 2012

HAL is a multi-disciplinary open access archive for the deposit and dissemination of scientific research documents, whether they are published or not. The documents may come from teaching and research institutions in France or abroad, or from public or private research centers.
L'archive ouverte pluridisciplinaire HAL, est destinée au dépôt et à la diffusion de documents scientifiques de niveau recherche, publiés ou non, émanant des établissements d'enseignement et de recherche français ou étrangers, des laboratoires publics ou privés. 
Age effect on the default mode network, inner thoughts and cognitive abilities

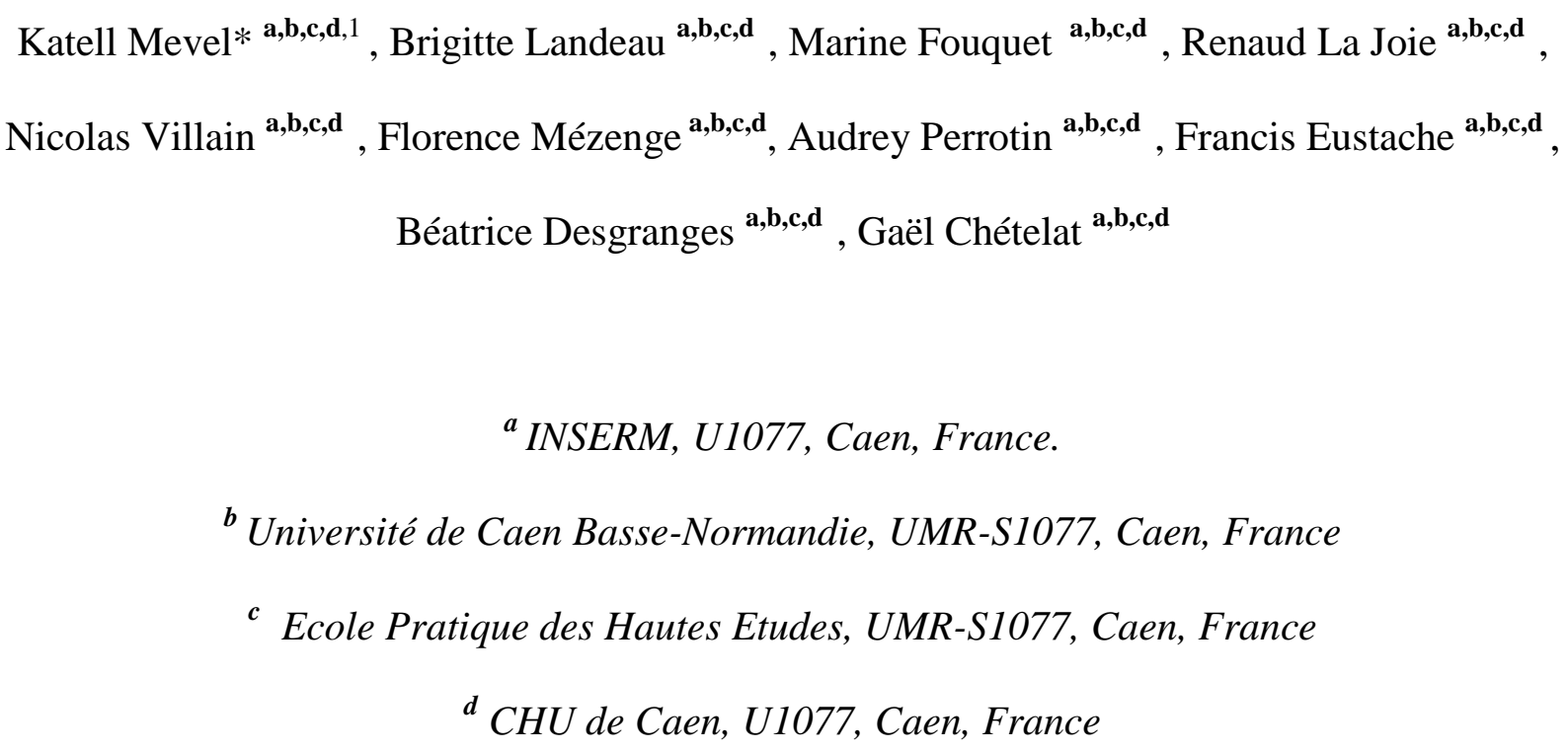

\section{Correspondence and Reprint Requests:}

Katell Mevel, Unité de recherche U1077, GIP Cyceron, Bd H. Becquerel, 14074 Caen cedex, France; Tel: +33 (0)2 314701 73; Fax: +33 (0)2 314702 75;

E-mail: mevel@cyceron.fr

Footnote: 1. Present address: Department of Women's and Children's Health, Astrid Lindgren Children's Hospital, Q2:07, Center of Neurodevelopmental Disorders (KIND), Karolinska Institute, SE-17176 Stockholm, Sweden 


\begin{abstract}
Age-related effects on the Default Mode Network (DMN) connectivity as measured at rest using functional MRI (fMRI) are now well described. Little is known however about the relationships between these changes and age-related effects on cognition or on the unconstrained thoughts occurring during the resting-state scan, called as inner experience. Brain resting-state activity, inner experience and cognitive ability measurements were obtained in 70 participants aged 19 to 80 years. The anterior-posterior disruption of DMN activity with age reported in previous studies was recovered here. A significant effect of age was also found on cognitive abilities but not on inner experience. Finally, age-related changes in DMN connectivity were found to correlate with cognitive abilities, and more specifically with autobiographical memory performance. These findings provide new information to fuel the debate on the role of the brain default mode and more specifically on the impact of agerelated changes in resting-state activity as measured with fMRI.
\end{abstract}

Keywords: aging; resting state; default mode network; functional connectivity; autobiographical memory; inner experience 


\section{Introduction}

Brain resting-state connectivity, as assessed with functional MRI (fMRI), refers to inter-regional synchrony of low frequency fluctuations (Biswal et al., 1995; see Deco et al., 2011 for a review). Brain regions showing such synchronous activity constitute a network and multiple large-scale spatially distributed networks can be detected at rest (see Van den Heuvel and Hulshoff Pol, 2010 for a review). The development and changes of resting-state networks is an on-going process across the human lifespan. Thus, anatomical segregation followed by functional integration processes allow the emergence of resting-state networks from early childhood to early adulthood. These networks are first organized by anatomical proximity, and progressively in a distributed manner across the brain (see Power et al., 2010 for a review). Then, normal aging induces resting-state activity changes so that older adults are characterized by connectivity modifications within these networks (Meunier et al., 2009). The Default Mode Network (DMN) is the resting-state network that received the greatest attention, as it was the first described, and contains brain regions critical for several cognitive functions and/or particularly sensitive to neurodegenerative diseases such as Alzheimer's disease (see Buckner et al., 2008 for a review; Damoiseaux et al., 2012; Greicius et al., 2004). Indeed, the DMN includes the ventral medial prefrontal (vmPFC), anterior and posterior cingulate (PCC) cortices, as well as the precuneus, the inferior parietal cortices/angular gyri and the hippocampi. It has been consistently shown that normal aging induces a connectivity disruption within the DMN, more specifically along the anterior-posterior axis of this network. According to this, decreases in co-activation between posterior regions, such as PCC, and anterior areas have been often reported in elderly (Andrews-Hanna et al., 2007, Biswal et al., 2010; Grady et al., 2010; Jones et al., 2011; Meunier et al., 2009; Wu et al., 2011). Note that none of these studies assessed linear versus non-linear age effects across the entire adulthood, as they did not include middle-aged participants or only tested linear effects. 
While changes with age in DMN connectivity have been described in several studies, the behavioural correlates of these changes remains largely unknown. There is a rich debate in the literacy around the cognitive role of the DMN (see Buckner and Carroll, 2007, Mevel et al., 2011 for reviews; Spreng et al., 2009 for a meta-analysis), but it is still unclear whether the (co)activity of the DMN nodes either reflects the participant's mental content during the scan, called as inner experience in what follows, or rather represents the brain base functioning of the individual, independent from the inner experience during the scan but potentially related to cognitive abilities. According to its specific topography, the DMN has been compared to several well-known networks. For instance, Buckner and Carroll (2007) underlined the remarkable similarity between the DMN and self-projection related networks such as remembering, theory of mind or prospection networks. Considering each region of the DMN separately, this network could be associated not only to the cognitive functions listed above but also to mental imagery or to the attention processes required for the monitoring of the external environment when focused attention is relaxed. Several studies have been conducted in young individuals, that reported a relationship between resting-state networks activity and inner experience (Doucet et al., 2012), daydreaming (Mason et al., 2007), or cognitive performances including episodic memory (Wang et al., 2010a), and executive function (Seeley et al., 2007). As for the specific question of the links between age-related DMN changes and behavioural measures, previous studies reported a relationship in older subjects between connectivity of i) the hippocampus in medial parietal areas and ii) medial prefrontal in inferior parietal DMN areas, and episodic memory retrieval but not non-memory performances (i.e. global functioning, processing speed and executive function; He et al., In Press; Wang et al., 2010b). Conversely, decreased shifting performances in older adults have been shown to be associated with activity fluctuations in more anterior parts of the DMN (Damoiseaux et al., 2008), as well as in the whole executive-control network (Gour et al., 
2011). However, there has been no study to date comparing the relationships between the functional connectivity within the main DMN nodes and both inner experience and cognitive abilities in normal aging. Consequently it is still unknown whether age-related changes in DMN activity rather reflect modifications in inner experience, decreases in cognitive performance or both.

The main goal of this study was thus to determine whether age-related changes in DMN connectivity are paralleled by changes with age in inner experience and/or cognitive abilities within a sample of healthy volunteers covering the whole adult lifespan. We hypothesized that the age-related changes in DMN connectivity, assumed to involve a disruption between anterior and posterior brain DMN areas, would be associated with agerelated changes in the inner experience during the scan and/or in cognitive performance.

\section{Methods}

\subsection{Participants}

Healthy subjects were enrolled in this study after detailed clinical and neuropsychological examinations. They were screened for the lack of abnormalities according to stringent inclusion/exclusion criteria including (1) normal somatic examination, (2) body mass index in the normal range, (3) no known vascular risk factor and smoking less than 10 cigarettes per day, (4) no alcohol or drug abuse, (5) blood pressure within normal limits (6) no history or clinical evidence of neurological disease, dementia or psychiatric disorder, (7) no current use of medication (except birth control pills, oestrogen replacement therapy and antihypertensive drugs), (8) normal standard T1- and T2-weighted MRI as assessed by a medical doctor. The Mattis dementia rating scale was used for subjects over 50 years old to exclude those with scores below the normal range for age. They all had performances in the normal range (i.e. within 1.65 standard deviation of the normal mean for age) in all screening neuropsychological tests (assessing episodic memory, semantic memory and executive 
functions) and no subject complained about his/her memory. This protocol was approved by the regional ethics committee (CCP Nord Ouest III) and subjects gave written informed consent to the study prior to the investigation.

Seventy right-handed native French-speaking participants, ranging from 19 to 80 years (mean age: $44 \pm 17.6$ years; 49 females; mean years of education: 13.4 \pm 3.5 ) and homogeneously distributed over the entire lifespan periods (Supplementary Table ST1), were included in our study. There was a significant decrease in years of education with age (Pearson's correlation $\mathrm{r}=-.39 ; \mathrm{p}=0.001)$ and a greater proportion of females $(21 \mathrm{males} / 49$ females). Both variables were thus corrected for in all statistical analysis.

\subsection{Resting state fMRI}

\subsubsection{Data acquisition}

A Philips (Eindhoven, The Netherlands) Achieva 3.0 T scanner from the GIP Cyceron (Caen, France) was used for data acquisition. For each participant, a high-resolution T1weighted anatomical volume was first acquired using a 3-dimensional fast field echo sequence (3D-T1-FFE sagittal), followed by a high-resolution T2-weighted spin echo anatomical acquisition (2D-T2-SE sagittal) and a non-EPI T2 *volume (2D-T2 *-FFE axial). Resting state functional acquisitions (RsfMRI) were obtained in the 70 subjects using an interleaved 2D T2*SENSE (SENSitivity Encoding) EPI sequence designed to reduce geometrical distortions by using parallel imaging, shorter echo time, and smaller voxels (2D$\mathrm{T} 2 *$-FFE-EPI axial, SENSE factor $=2 ; \mathrm{TR}=2382 \mathrm{~ms}$; TE $=30 \mathrm{~ms}$; flip angle $=80^{\circ} ; 42$ slices; slice thickness $=2.8 \mathrm{~mm}$; no gap; in-plane resolution $=2.8 \times 2.8 \mathrm{~mm}^{2} ; 280$ volumes) . The first six volumes were discarded due to saturation effects. Subjects were equipped with earplugs and their heads were stabilized with foam pads to minimize head motion. During this acquisition, which was the last one of the MRI scanning session, subjects were asked to relax, lie still in the scanner and keep their eyes closed while not falling asleep. Immediately after 
the scanning, the participants were invited to complete a semi-directed questionnaire especially designed for the evaluation of their inner experience during the resting state (see section 2.3. The post-scan interview: Inner Experience Questionnaire (InExQ); Supplementary Material S1).

\subsubsection{Data handling.}

Individual datasets were first checked for artefacts through the application of the TSDiffana routines (http://imaging.mrccbu.cam.ac.uk/imaging/DataDiagnostics), during which a variance volume was created for each subject to check that most signal variability was restricted to the cortex. Datasets showing evidence for significant movements (> $3 \mathrm{~mm}$ translation or 1.5 degree rotation) associated to image artefacts and/or an abnormal variance distribution were excluded $(\mathrm{n}=2)$. Only the 70 participants with usable data are referred to in the present article. The whole processing pipeline applied to each remaining subject dataset is detailed in Fig.1. Briefly, the EPI volumes were corrected for slice timing and realigned to the first volume. Data were then spatially normalized using a technique designed to reduce geometrical distortions effects (Villain et al., 2010). Briefly, this procedure includes for each individual (1) a coregistration of the mean EPI volume, non-EPI T2*, T2 and T1 volumes, (2) a warping of the mean EPI volume to match the non-EPI T2* volume, (3) a segmentation of the T1 volume using the VBM 5.1 'Segment' procedure with the International Consortium for Brain Mapping (ICBM)/Montreal Neurological Institute (MNI) priors, (4) a normalization of the coregistered T1, EPI, and non-EPI T2* volumes using the parameters obtained from the T1 segmentation, (5) a 4mm FWHM smooth of the EPI volumes. Finally, a binary mask was created from the group segmented mean gray matter T1 volume in conjunction with the mean non EPI-T2* volume in the MNI space (including only voxels with values above 0.25 in both mean images). 
Using the GIFT toolbox (http://icatb.sourceforge.net) and the gray matter T1-non EPI T2*mask described above, a group independent component analysis using temporal concatenation with Infomax algorithm implementation (Calhoun et al., 2001) was performed on the 70 individual datasets. The number of components was arbitrary set to 20 , allowing to extract a component that included all the brain regions known to compose the DMN, i.e. the PCC, mPFC/anterior cingulate cortices and lateral inferior parietal cortices (Fig. 2). The corresponding individual DMN z-maps were then obtained and smoothed at 6.9mm FWHM, in order to obtain a final smoothness of 8mm FWHM (i.e. first smooth ${ }^{2}+$ second smooth $^{2}=$ final smooth²; Poline et al., 1995).

For the purpose of functional connectivity analyses, the smoothed individual DMN zmaps were entered into SPM5 using the 'One-sample t-test' routine and thresholded to create an explicit mask of the DMN. The three most significant peaks of this analysis (Supplementary Table ST2) located within the right PCC [2 -52 16], the right angular gyrus [48 -64 30] as well as the left vmPFC [-4 56 -6] respectively, were used as seed coordinate centers for the functional connectivity analyses to assess age-related connectivity changes within the DMN. Thus, $6 \mathrm{~mm}$ radius spherical seeds based on these coordinates were created using the MarsBar toolbox (Brett et al., 2002) and the 70 individual mean time-courses were extracted for each seed. Then, for each seed, positive correlations were assessed between the mean time course in the seed and the time course of each voxel across the whole gray matter (both corrected for low-frequency drift using a temporal filtering of $0.008 \mathrm{~Hz}$ ), using the six parameters generated from realignment of head motion as covariates and the T1-non EPI T2* mask. A Fisher's z transform, as well as a $6.9 \mathrm{~mm}$ FWHM smooth, were then applied to the resulting individual connectivity maps (Fig.1).

\subsection{The post-scan interview: Inner Experience Questionnaire (InExQ)}

\subsubsection{Description of the $\operatorname{InExQ}$}


The semi-structured questionnaire used here, called as InExQ for Inner Experience Questionnaire, was especially designed for the evaluation of the participants' inner experience occurring while they were laying at-rest in the scanner. The main purpose was to propose a short and fast-completing questionnaire exploring the different domains relevant to assess the role of the DMN. The InExQ is described in details in the Supplementary Material S1, while only items selected for further analyses in the present study will be detailed below. Briefly, 18 questions in total were asked, according to five main topics or category of thoughts respectively assessing: i) the proportion of time spent thinking; ii) the verbal versus visual of thoughts; iii) the proportion of memories versus prospective thoughts, called as 'future intentions'; iv) the emotion associated with thoughts; and v) the self- versus non self-based nature of thoughts. The questions require the participant to answer either by quantitative values (i.e. number of thoughts in a particular category, called as 'numbers'), or qualitative answers (i.e. 'proportion' of one category of thoughts as compared to another one, e.g. verbal versus visual thoughts, using the stand alone slide) over the entire duration of the scan.

\subsubsection{InExQ scores handling}

The InExQ thus started with a few training and control items. Training items allowed the participants to familiarize with the stand-alone slide they had to use to answer (Supplementary Material S1). Control items were used to exclude participants who reported being in a drowsy state for more than $50 \%$ of the rsfMRI session (> $5 \mathrm{~min}$ ) and/or falling asleep during the examination; and/or showing a constant and focused mental activity about a single thing during the whole session. The total number of thoughts corresponding to the sum of declared memories, future intentions and mental scenarios, was computed for each participant in order to control for individual variability in the subsequent number analyses. Note that one participant was excluded from these analyses because he declared numbers ten times higher than the mean of the other individuals. Also, scores showing very low inter- 
subjects variability or too numerous missing values (as subjects did not encountered the event) were discarded from further analyses. Finally, the following scores were selected for subsequent analyses i) the time spent thinking, as well as one relative score per topic $(n=5)$, ii) the total amount of thoughts, the number of memories and future intentions. As a consequence, 9 different scores obtained in up to 69 participants were included in the statistical analyses of the InExQ (Table 1; Supplementary Table ST1).

\subsection{Cognitive abilities}

\subsubsection{Tests description}

Neuropsychological tests and scores have been selected amongst a more detailed neuropsychological battery based on the hypothesized roles of the DMN proposed in the literacy or because they are thought to be subtended by brain areas included in the DMN (see Introduction).

\subsubsection{Episodic memory assessment}

An autobiographical fluency task was used to assess the episodic aspect of autobiographical memory. This test has been extensively detailed in previous studies by our group (see Chételat et al., 2005 for instance). Briefly, participants were given instructions to recall as many personal events of their life as possible, during two minutes. Three periods were proposed and only the 'last 10 years minus the last one' period was considered in the present study. The sum of the episodic events for the 'last 10 years minus the last one' period thus corresponded to the episodic autobiographical memory score.

To assess the verbal episodic memory, we used the 'Encoding, Storage, Retrieval' paradigm fully described elsewhere (ESR; see Chételat et al., 2005 for instance). Briefly, participants had to recall as many words as possible from two distinct 16 word lists following either a superficial or a deep encoding phase. The sum of the two immediate free recalls was used as the measure of verbal episodic memory, the maximum score being 32 . 
An original test was used to investigate visual episodic memory named as the adapted BEM 144 (aBEM-144) in what follows. This test included the 12 graphic signs from the BEM 144 memory battery (Batterie d’Efficience Mnésique; Signoret, 1991), as well as new items to mimic the conditions of the ESR paradigm described above. Two lists of 8 items each were presented to the participants, following either a superficial or a deep encoding phase. Immediately after the studying phase of each list, participants had to recall as many items as possible (immediate free recall). The maximum score was 32 and the sum of the two immediate free recalls corresponded to the visual episodic memory score.

\subsubsection{Semantic memory assessment}

We used an autobiographical fluency task similar to that described above with personal events, but using the name of individuals that our participants have met in the past. As for the episodic autobiographical memory score, the sum of the correct individuals' names given for the 'last 10 years minus the last one' period was used as the semantic autobiographical memory score.

To assess semantic memory capacity, we used the category word fluency tasks (Cardebat et al., 1990), where participants had to produce in 2 minutes as many words as possible which complied with the 'animals' semantic criterion. The verbal semantic score was the sum of produced words that complied with the criterion.

\subsubsection{Daydreaming}

Daydreaming was tested using a 12-item scale based on the Imaginal Processes Inventory used by Mason et al. (2007). The participants had to indicate, for each item, the frequency of occurrence, as for instance: 'Remembering past events, thinking of future or unusual events takes: a) 0\%; b) less than 10\%; c) 10 to 25\%; d) 25 to 50\%, e) $50 \%$ or more ... of my daytime'. The answers were quoted from 1 to 5 and the daydreaming score 
corresponded to the sum of the 12 scores. The maximum total score was 60 , reflecting a high daydreaming propensity.

\subsubsection{Self-related processes}

Self-related processes were assessed using the certainty score of the Questionnaire of Self-Representations described in details elsewhere (QSR; Duval et al., 2012). Briefly, this questionnaire consisted of 50 positive or negative descriptive statements (e.g., 'I am an honest person'; 'I do not feel at ease with other people') which were rated for self-descriptiveness on a 4-point Likert-type scale ranging from (1)'Does not describe me at all' to (4) 'Describes me absolutely'. The certainty score gave information about the stability of self-representations. This score computed the numbers of definite responses, that is, responses rated "1" (Does not describe me at all) or "4" (Describes me absolutely), which corresponded to clear-cut and consistent self-representations; the other responses, i.e. "2" (Describes me a little) and "3" (Describes me well), were regarded as vague responses. Taking into account only the definite answers, percent total scores indicating stable self-representations were computed.

\subsubsection{Mental Imagery assessment}

The 'colours comparison' subtest of the Perception-Imagery Battery (PIB; Bourlon et al., 2009) was used to assess the participants' ability in generating mental pictures. The mental imagery generation score corresponded to the sum of correctly answered items $($ maximum $=30)$.

\subsubsection{Executive functions assessment}

Shifting capacities were assessed using the Trail Making Test (Time Part B - Part A).

\subsubsection{Handling of cognitive abilities scores}

Thirteen participants did not have the neuropsychological tests and a few individuals had incomplete testing so that in total the study samples were between 53 and 57 according to 
the neuropsychological score considered. Nine scores were then analysed from the tests described above (Table 1; Supplementary Table ST1).

\subsection{Statistical analyses}

\subsubsection{Age effects}

We aimed at assessing both linear and quadratic effects of age in each of the three experimental sets of variables, i.e. functional connectivity, InExQ and cognitive abilities. To that end, two statistical models were used entering either age (linear) or age $+\operatorname{age}^{2}$ (quadratic) as predictors, together with two regressors of non-interest (years of education and gender). Note that age and age $^{2}$ have first been orthogonalized before being entered together in the quadratic model. As for the InExQ numbers, the total amount of thoughts was also added as a regressor of non-interest. For both InExQ and cognitive abilities scores, adjusted $\mathrm{R}^{2}$ values associated to the whole model for each score were used to choose the best fit model (Table 1) and results were considered as significant when reaching $\mathrm{p}<0.05$ corrected for multiple comparisons, i.e. $\mathrm{p}<0.006$. For the linear and quadratic regressions on functional connectivity maps, the SPM5 'Multiple Regression' routine and an explicit masking procedure with the DMN binary mask were used. The results of the regression analysis were considered as significant at $\mathrm{p} \mathrm{FWE}<0.05, \mathrm{k}>30$ voxels and values were extracted for both models and each seed connectivity $\mathrm{R}^{2}$ maps within the most significant voxel peak to choose the best fit model (data not shown). Note that the effects of age on connectivity maps were also assessed in different conditions to strengthen our conclusion and check whether our findings depended on methodological choices. Thus, the regression analyses were repeated i) from connectivity maps obtained using the whole cluster as a seed instead of a sphere, ii) adding the individual gray matter maps as a regressor, and iii) using ANCOVAs routines with 3 age-groups as a complementary way of assessing the age effects to confirm our findings. Since the results of 
all these confirmatory analyses were similar to those observed using the procedure described above (Supplementary Material S3), only the latter will be presented in what follows.

\subsubsection{Relationships between brain RsfMRI, InExQ or cognitive abilities}

Each of the 9 InExQ scores and 9 neuropsychological assessment performances showing a significant age effect was correlated to the three functional connectivity datasets. This was achieved by using the SPM5 'Multiple regression' routine with years of education and gender, as well as the total amount of thoughts if required, as regressors of non-interest. Results were considered as significant at $\mathrm{p} \mathrm{FWE}<0.05, \mathrm{k}>30$ voxels.

\section{Results}

\subsection{Age effects on DMN connectivity}

The right PCC connectivity maps showed significant linear decreases with age in the right vmPFC/orbitofrontal [4 $62-6$ ] $\left(\mathrm{k}=316, \mathrm{~T}=6.94, \mathrm{p} \mathrm{FWE}=7 \times 10^{-6}\right)$ and the right ventral PCC [12 -64 26] (k=34, p FWE=0.003, T= 5.24) (Fig. 3a). The left vmPFC connectivity maps showed significant linear decreases in connectivity within the right vmPFC/orbitofrontal [2 60 -6] $\left(\mathrm{k}=146, \mathrm{~T}=6.03, \mathrm{p}\right.$ FWE $\left.=1.96 \times 10^{-4}\right)$, the left ventral PCC [-8 -46 30] $(\mathrm{k}=39, \mathrm{~T}=5.36, \mathrm{p}$ $\mathrm{FWE}=0.002)$ and the right precuneus/PCC [2 -54 18] (k=34, pFWE=0.009, T=4.90) (Fig. 3b). There was no linear decrease of the right angular functional connectivity, and there were no significant linear increases of the three seed connectivity, even when lowering the threshold to $\mathrm{p}$ uncorrected $<0.001$. Finally, the quadratic models did not lead to significantly higher $\mathrm{R}^{2}$ values compared to the linear model.

\subsection{Age effects on $\operatorname{InEx} Q$ scores}

No significant age effects were found on the scores obtained from the InExQ questionnaire (Table 1).

\subsection{Age effects on cognitive abilities}


A significant linear effect of age was found for all episodic memory scores, for the semantic autobiographical memory score, and for performances in shifting. Adding age ${ }^{2}$ did not significantly improve the model, e.g. the quadratic model provided similar $\mathrm{R}^{2}$ values as those obtained through the linear one (Table 1).

\subsection{Correlations between DMN connectivity and cognitive abilities}

Only the performances in autobiographical memory correlated with functional connectivity. First, positive correlations were found between episodic autobiographical memory fluency scores and the right PCC connectivity with the left middle [-68 -22 -14] $\left(\mathrm{k}=56, \mathrm{~T}=6.41, \mathrm{p} F \mathrm{FWE}=1.6 \times 10^{-4}\right)$ and right inferior $\left[\begin{array}{lll}54 & 6 & -30\end{array}\right](\mathrm{k}=107, \mathrm{~T}=6.16, \mathrm{p}$ $\mathrm{FWE}=3.6 \times 10^{-4}$ ) temporal cortices, the right amygdala/anterior hippocampus $\left[\begin{array}{lll}14 & -6 & -14\end{array}\right]$ $\left(\mathrm{k}=247, \mathrm{~T}=6.15, \mathrm{p} F \mathrm{FW}=3.7 \times 10^{-4}\right)$ and the right middle temporal cortex $[54-10-14,(\mathrm{k}=72$, $\mathrm{T}=5.44$, p FWE=0.003) (Fig. 4a). Second, positive correlations were observed between semantic autobiographical memory fluency scores and i) the left vmPFC connectivity with the right ventral anterior cingulate [8 $34-12](\mathrm{k}=140, \mathrm{~T}=5.51, \mathrm{p} F W E=0.002)$ and ii) the right angular connectivity in the right primary visual/retrosplenial cortex [4 -62 10] $(\mathrm{k}=44, \mathrm{~T}=5.37$, p FWE=0.004) (Fig. 4b).

\section{Discussion}

Altogether, the present study shows that age has a strong and linear effect on brain resting-state connectivity within the DMN. More specifically, we found decreased connectivity between anterior and posterior regions of the DMN with increasing age. As regard to the inner experience during the scan, we found no significant (linear or non-linear) effects of age on the measures obtained from the InExQ, suggesting that the content of thoughts does not significantly change with age. By contrast, performances in autobiographical and episodic memory tasks, as well as shifting were found to decrease with age. Finally, age-related changes in brain functional connectivity were found to be paralleled 
by changes in both semantic and episodic autobiographical memory scores. Altogether, our findings suggest that age-related changes in DMN connectivity are not paralleled by changes in the content of the inner experience during the resting-state scan, but are associated with cognitive ability changes with age and more specifically with autobiographical memory performances.

\subsection{Age related effects on DMN connectivity}

As regard to the effects of age on DMN connectivity, our results bring support to the anterior-posterior disruption of activity reported by previous studies. Indeed, we showed that the connectivity between PCC and vmPFC regions was strongly and linearly decreased as age increased. This result is consistent with previous findings, highlighting a disruption of connectivity at-rest along the anterior-posterior axis of the DMN (Andrews-Hanna et al., 2007; Grady et al., 2010; Wu et al., 2011). As suggested by Andrews-Hanna et al. (2007), this could be explained by an age-related decrease in white matter integrity, associated to gray matter atrophy and/or neurotransmitter depletion. Consistent with this hypothesis, the authors showed a strong negative correlation between fractional anisotropy measurements in several white matter bundles and the extent of the anterior-posterior disruption within the DMN. Moreover, age-related cortical atrophy probably only accounts for a small part of variability in the functional disruption pattern, as suggested by our complementary analysis with gray matter maps as a regressor (Supplementary Material S3) and consistently with a previous report (Wu et al., 2011).

\subsection{Age related effects on inner experience}

The InExQ revealed patterns of inner experience similar to that reported in previous studies. Indeed, it shows a high prevalence of self-related thoughts (Fransson, 2005; Delamillieure et al., 2010), mental images, inner speech, and planning for the future (Fransson, 2005; see scores $>50 \%$ in Supplementary Table ST3). Further comparisons with 
previous reports are however complicated by the fact that the questionnaires are not comparable or the results poorly detailed. As regard to the effects of age, our findings suggest that normal aging does not significantly affect inner experience, i.e. that the content of the thoughts occurring during rest remained mostly unchanged with age (Table 1). Further works are needed to confirm this statement given the subjective, domain-restricted content of the questionnaire and the fact that it is the first study to assess the effect of age on inner experience. However, it is to note that this potential absence of changes in inner experience with age occurs despite significant changes in DMN functional connectivity, which interestingly suggests that age-related changes in DMN connectivity are not associated to agerelated modifications in the content of thoughts. Note that, consistent with this interpretation, there was no significant correlation between DMN connectivity and InExQ scores in the present study (data not shown).

\subsection{Age related effects on cognitive abilities}

Normal aging effects on cognitive performances as reported here are in line with the patterns previously highlighted (see Fjell and Walhovd, 2010 for a review). Indeed, we found reduced performances in our oldest participants for all episodic memory scores as well as for the shifting score (Table 1; Supplementary Table ST4). As regards to autobiographical memory specifically, both the episodic and semantic scores were significantly lower in older participants. This is also in agreement with previous findings suggesting that autobiographical memory deficits in healthy aging are largely mediated by performances in executive functions (Piolino et al., 2010). More precisely, autobiographical memory difficulties in aging are assumed to result mainly from a deficit on strategic processes - within the frontal/executive system, which are necessary to recollect elements in autobiographical memory. Our results of a combined disturbance in shifting and autobiographical memory abilities are thus consistent with this frontal/executive hypothesis of aging. 


\subsection{Linear versus non-linear age effects}

Note that we did not observe any quadratic age effect on DMN connectivity, inner experience or cognitive abilities, which suggests that changes are rather linear. While there is no comparable study, non-linear effects of age have been reported in previous studies on the whole-brain functional connectivity at-rest (in homotopic regions; Zuo et al., 2010) or on cognition (Finkel et al., 2007). Methodological differences between these previous works and ours, notably in the type of measurements and the age range of the studied population, are likely to account for these discrepancies. For instance, Zuo et al. investigated resting-state homotopic connectivity in a sample aged 7-85 years. Though they found that a quadratic model best fitted age effects on the average whole-brain homotopic connectivity, the patterns they reported were also linear, quadratic or cubic according to the region considered. Since we did not investigate resting-state homotopic, but DMN inter-regional connectivity, and because the present study was the first to assess linear versus quadratic on brain connectivity within the DMN, further comparisons with previous works are made difficult. Replication on larger samples would be also needed to confirm the absence of non-linear effects. Similarly, while Finkel and colleagues reported quadratic age effects on a multicomponent memory score, i.e. a score including working, long-term visual and associative memory performances, within a sample aged over 50 years, we investigated isolated measures in a sample including young to aged participants.

\subsection{Relationships between DMN connectivity and cognitive abilities}

Both episodic and semantic fluency autobiographical memory scores were found to correlate with connectivity changes in the DMN (Fig. 4), and both variables also showed a significant effect of age so that performance decreased with increasing age. Note that it is unlikely that our findings simply reflect a common effect of age on both autobiographical memory and interregional connectivity at rest as i) a significant DMN-score correlation was 
not found for all cognitive performances shown to significantly decrease with age - e.g. a significant effect of age was found on shifting performances but no correlation was found between this score and DMN nodes connectivity; ii) the results remained the same, though less significant and extended, when adding age and age ${ }^{2}$ as regressors in the correlation analyses (data not shown). Thus, our findings rather suggest that DMN disturbances with age are specifically related to episodic and semantic autobiographical memory performances. Moreover, as predicted by previous studies exploring the brain networks associated with autobiographical memory subcomponents (Piolino et al., 2009; see Svoboda et al., 2006 for a meta-analysis), we also found differential patterns of correlations according to the subcomponent considered. Interestingly, a positive correlation was found between the episodic autobiographical memory score and the PCC connectivity in bilateral temporal regions, including the hippocampus (Fig. 4a). This specific interaction between medial parietal and temporal regions is in agreement with the cerebral models of autobiographical memory (Piolino et al., 2009; Svoboda et al., 2006) as well as with the findings of Wang et al. (2010b), that highlights the importance of the interaction between the PCC and the hippocampus for episodic memory retrieval in aged participants. Finally, our results are also in line with studies highlighting the implication of brain medial areas for the processing of self-referential stimuli in the context of one's own person (Northoff and Bermpohl, 2004), a process especially involved in autobiographical memory tasks (Fig. 4).

\subsection{Conclusion}

The present study assessed for the first time the relationships between age-related effects on resting-state brain connectivity, inner experience occurring during the scanning session and cognitive abilities. It showed a significant effect of age on DMN connectivity and cognitive abilities, while inner experience seems relatively unchanged. Moreover, changes with age in DMN connectivity correlated to changes in cognitive abilities, and more 
specifically to autobiographical memory performances. These findings suggest that agerelated changes in the DMN reflect modifications in brain functioning integrity, in relation to cognitive integrity, rather than in the content of the thoughts during the scan. This in turn suggests that DMN integrity measurements may be of interest to detect brain alterations in pathological states such as

Alzheimer's disease. 
Acknowledgements: This work was supported by Agence Nationale de la Recherche (ANR LONGVIE 2007), Programme Hospitalier de Recherche Clinique (PHRC National 2008), Région Basse Normandie and Institut National de la Santé et de la Recherche Médicale (Inserm). The authors gratefully acknowledge R. Almeida, C. Duval, S. Egret, M. Gaubert, M. Groussard, K. Lebouleux, N. Morel, M-H. Noël, M-C. Onfroy, G. Perchey, P. Piolino and all the participants.

Disclosure statement: The authors have no actual or potential conflicts of interest to disclose. 


\section{References}

Andrews-Hanna, J.R., Snyder, A.Z., Vincent, J.L., Lustig, C., Head, D., Raichle, M.E., Buckner, R.L., 2007. Disruption of large-scale brain systems in advanced aging. Neuron 56, 924-935.

Biswal, B., Yetkin, F. Z., Haughton, V. M., Hyde, J. S., 1995. Functional connectivity in the motor cortex of resting human brain using echo-planar MRI. Magn. Reson. Med. 34, 537541.

Biswal, B.B, Mennes, M., Zuo, X.N., Gohel, S., Kelly, C., Smith, S.M., Beckmann, C.F., Adelstein, J.S., Buckner, R.L., Colcombe, S., Dogonowski, A.M., Ernst, M., Fair, D., Hampson, M., Hoptman, M.J., Hyde, J.S., Kiviniemi, V.J., Kötter, R., Li, S.J., Lin, C.P., Lowe, M.J., Mackay, C., Madden, D.J., Madsen, K.H., Margulies, D.S., Mayberg, H.S., McMahon, K., Monk, C.S., Mostofsky, S.H., Nagel, B.J., Pekar, J.J., Peltier, S.J., Petersen, S.E., Riedl, V., Rombouts, S.A., Rypma, B., Schlaggar, B.L., Schmidt, S., Seidler, R.D., Siegle, G,J., Sorg, C., Teng, G.J., Veijola, J., Villringer, A., Walter, M., Wang, L., Weng, X.C., Whitfield-Gabrieli, S., Williamson, P., Windischberger, C., Zang, Y.F., Zhang, H.Y., Castellanos, F.X., Milham, M.P., 2010. Toward discovery science of human brain function. Proc. Natl. Acad. Sci. U.S.A. 107, 4734-4739.

Bourlon, C., Chokron, S., Bachoud-Lévi, A.C., Coubard, O., Bergeras, I., Moulignier. A., Viret, A.C., Bartolomeo, P., 2009. [Presentation of an assessment battery for visual mental imagery and visual perception]. Rev. Neurol. 165,1045-1054.

Brett, M., Anton, J-L., Valabregue, R., Poline, J-B., 2002. Region of interest analysis using an SPM toolbox [abstract] Presented at the 8th International Conference on Functional Mapping of the Human Brain, June 2-6, Sendai, Japan.

Buckner, R.L., Carroll, D.C., 2007. Self-projection and the brain. Trends Cogn. Sci. 11, 4957. 
Buckner, R.L., Andrews-Hanna, J.R., Schacter, D.L., 2008. The brain's default network: anatomy, function, and relevance to disease. Ann. N. Y. Acad. Sci. 2008, 1124, 1-38.

Calhoun, V.D., Adali, T., Pearlson, G.D., Pekar, J.J., 2001. A method for making group inferences from functional MRI data using independent component analysis. Human Brain Mapping 14,140-151.

Cardebat, D., Doyon, B., Puel, M., Goulet, P., Joanette, Y., 1990. Evocation lexicale formelle et sémantique chez des sujets normaux : Performances et dynamiques de production en fonction du sexe, de l'âge et du niveau d'étude. Acta Neurol. Belg. 90, 207-217.

Chételat, G., Eustache, F., Viader, F., de la Sayette, V., Pelerin, A., Mezenge, F., Hannequin, D., Dupuy, B., Baron, J-C., Desgranges, B., 2005. FDG-PET measurement is more accurate than neuropsychological assessments to predict global cognitive deterioration in patients with mild cognitive impairment. Neurocase 11, 14-25.

Damoiseaux, J.S., Beckmann, C.F., Arigita, E.J., Barkhof, F., Scheltens, P., Stam, C.J., Smith, S.M., Rombouts, S.A., 2008. Reduced resting-state brain activity in the "default network" in normal aging. Cereb. Cortex 18,1856-1864.

Damoiseaux, J.S., Prater, K.E., Miller, B.L., Greicius, M.D., 2012. Functional connectivity tracks clinical deterioration in Alzheimer's disease. Neurobiol. Aging, 33, 828.e19-30.

Deco, G., Jirsa, V.K., McIntosh, A.R., 2011. Emerging concepts for the dynamical organization of resting-state activity in the brain. Nat. Rev. Neurosci. 12, 43-56.

Delamillieure, P., Doucet, G., Mazoyer, B., Turbelin, M-R., Delcroix, N., Mellet, E., Zago, L., Crivello, F., Petit, L., Tzourio-Mazoyer, N., Joliot, M., 2010. The resting state questionnaire: An introspective questionnaire for evaluation of inner experience during the conscious resting state. Brain Res. Bull. 81, 565-573.

Doucet, G., Naveau, M., Petit, L., Zago, L., Crivello, F., Jobard, G., Delcroix, N., Mellet, E., Tzourio-Mazoyer, N., Mazoyer, B., Joliot, M., 2012. Patterns of hemodynamic low- 
frequency oscillations in the brain are modulated by the nature of free thought during rest. NeuroImage 59, 3194-3200.

Duval, C., Desgranges, B., de la Sayette, V., Belliard, S., Eustache, F. Piolino, P., 2012. What happens to personal identity when semantic knowledge degrades? A study of the self and autobiographical memory in semantic dementia. Neuropsychologia 50, 254-265.

Finkel, D., Reynolds, C.A., McArdle, J.J., Pedersen, N.L., 2007. Cohort differences in trajectories of cognitive aging. J. Gerontol. B. Psychol. Sci. Soc. Sci. 62, 286-294.

Fjell, A.M., Walhovd, K.B, 2010. Structural brain changes in aging: courses, causes and cognitive consequences. Rev. Neurosci. 23, 187-221.

Fransson, P., 2005. Spontaneous low-frequency BOLD signal fluctuations: an fMRI investigation of the resting-state default mode of brain function hypothesis. Hum. Brain Mapp. 26, 15-29.

Gour, N., Ranjeva, J.P., Ceccaldi, M., Confort-Gouny, S., Barbeau, E., Soulier, E., Guye, M., Didic, M., Felician, O., 2011. Basal functional connectivity within the anterior temporal network is associated with performance on declarative memory tasks. Neuroimage 58, 687-697.

Grady, C.L., Protzner, A.B., Kovacevic, N., Strother, S.C., Afshin-Pour, B., Wojtowicz, M., Anderson, J.A., Churchill, N., McIntosh, A.R., 2010. A multivariate analysis of agerelated differences in default mode and task-positive networks across multiple cognitive domains. Cereb. Cortex 20, 1432-1447.

Greicius, M.D., Srivastava, G., Reiss, A.L., Menon, V., 2004. Default-mode network activity distinguishes Alzheimer's disease from healthy aging: evidence from functional MRI. Proc. Natl. Acad. Sci. USA 101, 4637-4642. 
He, J., Carmichael, O., Fletcher, E., Singh, B., Iosif, A.M., Martinez, O., Reed, B., Yonelinas, A., Decarli, C. Influence of functional connectivity and structural MRI measures on episodic memory. Neurobiol. Aging, In Press, doi: 10.1016/j.neurobiolaging.2011.12.029.

Jones, D.T., Machulda, M.M., Vemuri, P., McDade, E.M., Zeng, G., Senjem, M.L., Gunter, J.L., Przybelski, S.A., Avula, R.T., Knopman, D.S., Boeve, B.F., Petersen, R.C., Jack, C.R. Jr., 2011. Age-related changes in the default mode network are more advanced in Alzheimer disease. Neurology 77, 1524-1531.

Mason, M.F., Norton, M.I., Van Horn, J.D., Wegner, D.M., Grafton, S.T., Macrae, C.N., 2007. Wandering minds: the default network and stimulus-independent thought. Science 315, 393-395.

Meunier, D., Achard, S., Morcom, A., Bullmore, E. T., 2009. Age-related changes in modular organization of human brain functional networks. Neuroimage 44, 715-723.

Mevel, K., Chételat, G., Eustache, F., Desgranges, B., 2011. The default mode network in healthy aging and Alzheimer's disease. Int. J. Alzheimers Dis., 2011:535816.

Northoff, G., Bermpohl, F., 2004. Cortical midline structures and the self. Trends Cogn. Sci. $8,102-107$.

Piolino, P., Desgranges, B., Eustache, F., 2009. Episodic autobiographical memories over the course of time: cognitive, neuropsychological and neuroimaging findings. Neuropsychologia 47, 2314-2329.

Piolino, P., Coste, C., Martinelli, P., Macé, A.L., Quinette, P., Guillery-Girard, B., Belleville, S., 2010. Reduced specificity of autobiographical memory and aging: do the executive and feature binding functions of working memory have a role? 2010. Neuropsychologia 8, 429-440. 
Poline, J.B., Worsley, K.J., Holmes, A.P., Frackowiak, R.S. Friston, K.J., 1995. Estimating smoothness in statistical parametric maps: variability of $\mathrm{p}$ values. J. Comput. Assist. Tomogr. 19, 788-796.

Power, J.D., Fair, D.A., Schlaggar, B.L., Petersen, S.E., 2010. The development of human functional brain networks. Neuron 67, 735-748.

Seeley, W.W., Menon, V., Schatzberg, A.F., Keller, J., Glover, G.H., Kenna, H., Reiss, A.L., Greicius, M.D., 2007. Dissociable intrinsic connectivity networks for salience processing and executive control. J. Neurosci. 27, 2349-2356.

Signoret, J-L., 1991. Batterie d'efficience mnésique. Paris: foundation IPSEN; Amsterdam: Elsevier.

Spreng, R.N., Mar, R.A., Kim, A.S., 2009. The common neural basis of autobiographical memory, prospection, navigation, theory of mind, and the default mode: a quantitative meta-analysis. J. Cogn. Neurosci. 21, 489-510.

Svoboda, E., McKinnon, M.C., Levine, B., 2006. The functional neuroanatomy of autobiographical memory: a meta-analysis. Neuropsychologia 44, 2189-2208.

Van den Heuvel, M.P., Hulshoff Pol, H.E., 2010. Exploring the brain network: a review on resting-state fMRI functional connectivity. Eur. Neuropsychopharmacol. 20, 519-534.

Villain, N., Landeau, B., Groussard, M., Mevel, K., Fouquet, M., Dayan, J., Eustache, F., Desgranges, B., Chételat, G., 2010. A simple way to improve anatomical mapping of functional brain imaging. J. Neuroimaging 20, 324-33.

Wang, L., Negreira, A., LaViolette, P., Bakkour, A., Sperling, R.A., Dickerson, B.C., 2010a. Intrinsic interhemispheric hippocampal functional connectivity predicts individual differences in memory performance ability. Hippocampus 20, 345-351.

Wang, L., Laviolette, P., O'Keefe, K., Putcha, D., Bakkour, A., Van Dijk, K.R., Pihlajamäki, M., Dickerson, B.C., Sperling, R.A., 2010b. Intrinsic connectivity between the 
hippocampus and posteromedial cortex predicts memory performance in cognitively intact older individuals. Neuroimage 51, 910-917.

Wu, J.T., Wu, H.Z., Yan, C.G., Chen, W.X., Zhang, H.Y., He, Y., Yang, H.S., 2011. Agingrelated changes in the default mode network and its anti-correlated networks: A restingstate fMRI study. Neurosci. Lett. 504, 62-67.

Zuo, X.N., Kelly, C., Di Martino, A., Mennes, M., Margulies, D.S., Bangaru, S., Grzadzinski, R., Evans, A.C., Zang, Y.F., Castellanos, F.X., Milham, M.P., 2010. Growing together and growing apart: regional and sex differences in the lifespan developmental trajectories of functional homotopy. J. Neurosci. 30, 15034-15043. 
Table 1: Correlations between InExQ scores, cognitive abilities and (a) age in the linear model or (b) orthogonalized age and age ${ }^{2}$ in the quadratic model; corrected for years of education and gender as well as for the total amount of thoughts for the InExQ numbers, and the corresponding whole-model adjusted $\mathrm{R}^{2}$ (in $\%$ ), $\beta$ and $\mathrm{p}$ values.

Key: $\mathrm{aR}^{2}$, adjusted coefficient of determination in percent.

Note: significant effect of age at $\mathrm{p}<0.006$ corrected for multiple comparisons is indicated in bold with *. 
Fig.1: Workflow diagram. This diagram shows the procedure used to process the rsfMRI data. More details are available in the Methods section.

Key: a, slice-time corrected; Ang, Angular Gyrus; c1, segmented gray matter; DMN, Default Mode Network; PFvM, Prefrontal Ventromedial cortex; PCC, Posterior Cingulate Cortex; r, coregistered (realigned); s, Gaussian smoothed; w, normalized. 
Fig. 2: Overlay of the results of the One Sample T-test (70 DMN z-maps; p FWE =0.05) on the group mean normalized T1 volume. Left side of the brain is displayed on the left side of the pictures. See Supplementary Table ST2 for details on the peak statistics and coordinates. 
Fig. 3: Negative linear age effects on the right PCC (a.) and the left vmPFC (b.) functional connectivity within the DMN obtained from the voxelwise analyses thresholded at $\mathrm{p}$ FWE $<0.05, \mathrm{k}>30$ voxels in SPM5 (i) and plot of the connectivity value of the main cluster peak against age, corrected for education level and gender (ii). Left side of the brain is displayed on the left side of the pictures. 
Fig. 4: Positive correlations between the functional connectivity of the $3 \mathrm{DMN}$ seeds and performances in the autobiographical fluencies. For the sake of illustration, results are displayed at $\mathrm{p}$ uncorrected $=0.001, \mathrm{k}>30$ voxels. Left side of the brain is displayed on the left side of the pictures.

Key: R, right, L, left. 
Table 1 


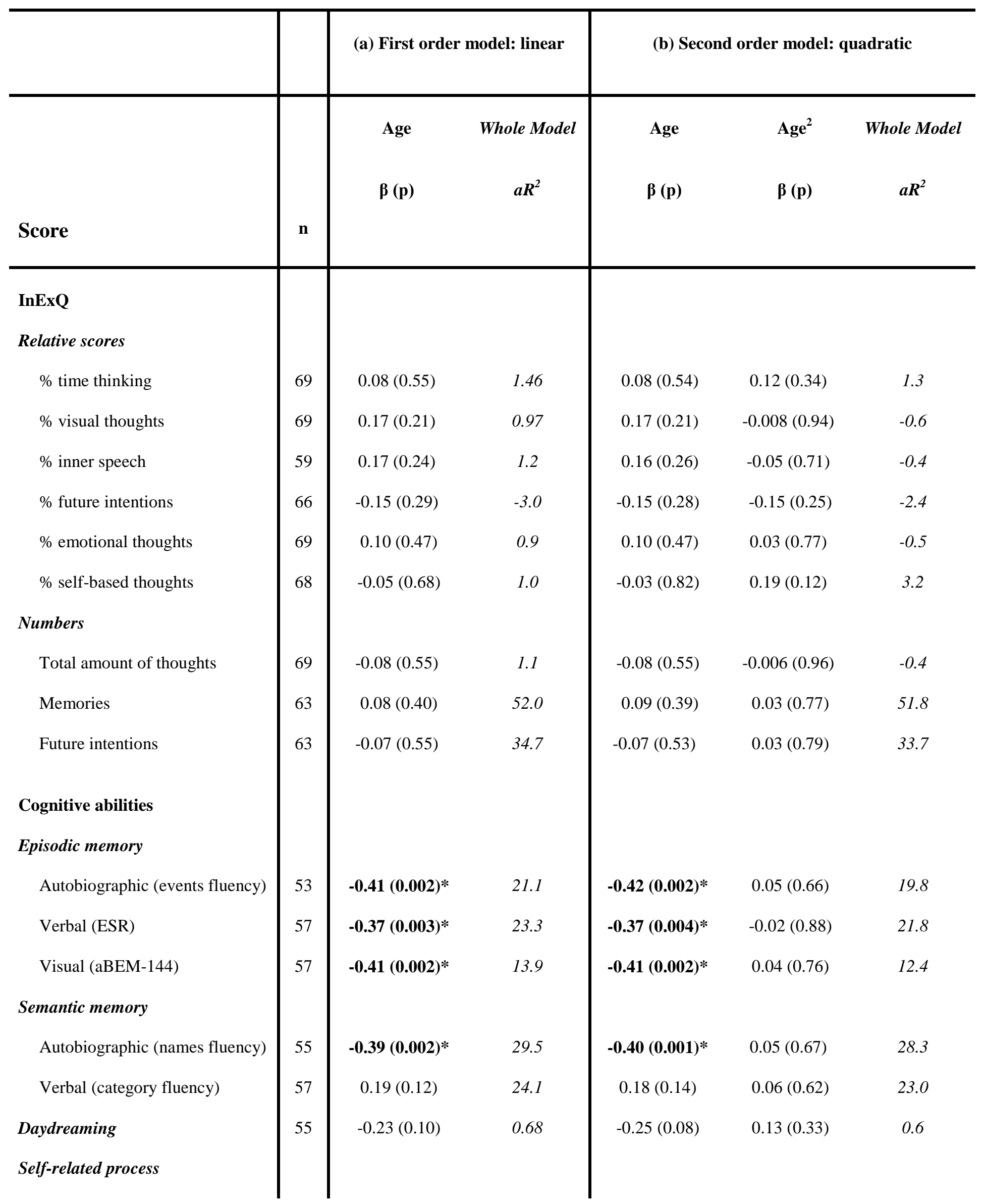




\begin{tabular}{|c|c|c|c|c|c|c|}
\hline Self certainty (SQR) & 55 & $0.13(0.35)$ & 0.39 & $0.15(0.27)$ & $-0.20(0.14)$ & 2.8 \\
\hline \multicolumn{7}{|l|}{ Mental imagery } \\
\hline Generation of pictures (PIB) & 55 & $0.22(0.10)$ & 8.3 & $0.21(0.12)$ & $0.08(0.56)$ & 7.1 \\
\hline \multicolumn{7}{|l|}{ Executive functioning } \\
\hline Shifting (TMT-time) & 56 & $0.39(0.001)^{*}$ & 30.0 & $0.37(0.002) *$ & $0.17(0.14)$ & 31.6 \\
\hline
\end{tabular}




\section{1- Supplementary material S1: the InExQ (Inner Experience Questionnaire)}

Section 1: The questionnaire started with two training questions designed to familiarize the participant to the slide they had to use to answer. This was a stand-alone plastic slide with two sides, one presented to the participant and showing a $10 \mathrm{~cm}$ colourful ungraduated rectangle with a moving curser, and the other graduated along the $10 \mathrm{~cm}$ and only made visible to the experimenter. The participants had to position the curser between the two extremities that corresponded to opposite answers to the question, e.g. 'Yes' and 'No for the questions 'In general, are you optimistic?, or 'happy' and 'Unhappy" for the question 'In general, are you happy or unhappy?' with all intermediate positions corresponding to intermediate answers between these extremes. The examiner could then record the position of the cursor thanks to the graduated scale, so that the answer of the subject could be translated in percentages (proportions)

Section 2: Participants were asked about their ability to stay alert during the fMRI scan, as well as to report any sensation they have encountered during the scan, i.e. pain, skin sensations, hunger, breathing, noises, others. For each item they answered positively, they were asked to specify the frequency and the duration.

Section 3: In this section, participants were asked questions about their inner experience occurring during the resting-state scan. A total amount of 18 questions were asked, according to five main topics or category of thoughts respectively assessing: i) the proportion of time spent thinking; ii) the verbal versus visual nature of thoughts; iii) the proportion of memories versus future intentions; iv) the emotion associated with thoughts; and v) the self- versus non self-focused nature of thoughts. 


\section{Section 3.1. Proportions}

The participants had to answer considering the whole resting-state fMRI examination and using the stand-alone slide.

First topic: Each participant was asked to give the proportion of time spent thinking.

Second topic: Each participant was asked to specify the proportion of verbal-or visual-based thoughts they had. The first category refers to verbalizations or any verbal material occurring while thinking. The second category refers to mental imagery, that is, thoughts in the shape of images (Kosslyn, 1994) and/or the faculty whereby we can imagine or "visualize" objects and places in their absence (Bourlon et al., 2011).

Immediately after this first question, they had to characterize both categories of thoughts. To do so, they had to specify the proportion of the i) verbal-based thoughts that were 'inner speech' (thinking in words with our own voice) or 'other auditory stimuli' based and/or ii) the proportion of the visual-based thoughts that included clear, detailed or blurred images.

Third topic: Each participant was asked to specify the proportion of memories or future intentions they had. The first category corresponds to personal events recollection while the second one corresponds to things that have to be done or events that could happen afterwards.

Immediately after this first question, they were asked to characterize the memories that occurred during the scanning by specifying the proportion of detailed or blurred memories.

Fourth topic: Each participant was asked to specify the proportion of thoughts that were associated to emotions during the recollection. Then they had to give details about the valence of their emotional thoughts, i.e. the proportion of thoughts associated to positive or negative emotions during the recollection.

Fifth topic: Each participant was asked to give the proportion of thoughts that were self- or non self-based. The first category corresponds to thoughts that are focused on the participant 
and his/her relatives, while the second type refers to thoughts focusing on items that are not directly linked to the participant and relatives.

\section{Section 3.2. Numbers}

In addition to the proportions detailed above, the participants were also asked to give the total amount of i) general memories; ii) episodic memories (events that lasted for less than 24 hours, occurred once, were spatially and timely defined and recollected with vivid details); iii) future intentions; iv) mental scenarios and v) emotional thoughts they had during the fMRI scan. As defined by Buckner et al. (2008), mental scenarios correspond to dynamic mental simulations generated when imagining alternative perspectives and scenarios to the present. 


\section{2- Supplementary Material S2: tables}

Table ST1: Demographic details of the participants included for brain resting-state, InExQ and cognitive abilities assessments

\begin{tabular}{|c|c|c|c|c|c|}
\hline & \multirow[b]{2}{*}{$\mathrm{n}$} & \multirow[b]{2}{*}{ Male/Female } & \multicolumn{3}{|c|}{ Group } \\
\hline & & & $\begin{array}{c}\text { Young } \\
\text { n (age range) }\end{array}$ & $\begin{array}{c}\text { Middle- } \\
\text { aged } \\
\text { n (age range) }\end{array}$ & $\begin{array}{c}\text { Aged } \\
\text { n (age range) }\end{array}$ \\
\hline Brain resting-state & 70 & $21 / 49$ & $26(19-32)$ & $23(36-59)$ & $21(60-80)$ \\
\hline InExQ & 69 & $21 / 48$ & $26(19-32)$ & $23(36-59)$ & $20(60-80)$ \\
\hline \multicolumn{6}{|l|}{ Relative scores } \\
\hline$\%$ time thinking & 69 & $21 / 48$ & $26(19-32)$ & $23(36-59)$ & $20(60-80)$ \\
\hline$\%$ visual thoughts & 69 & $21 / 48$ & $26(19-32)$ & $23(36-59)$ & $20(60-80)$ \\
\hline$\%$ inner speech & 59 & $15 / 44$ & $24(19-32)$ & $20(36-59)$ & $15(60-73)$ \\
\hline$\%$ future intentions & 66 & $21 / 45$ & $24(19-32)$ & $23(36-59)$ & $19(60-73)$ \\
\hline$\%$ emotional thoughts & 69 & $21 / 48$ & $26(19-32)$ & $23(36-59)$ & $20(60-80)$ \\
\hline$\%$ self-based thoughts & 68 & $21 / 47$ & $26(19-32)$ & $23(36-59)$ & $19(60-73)$ \\
\hline \multicolumn{6}{|l|}{ Numbers } \\
\hline Total amount of thoughts & 69 & $21 / 48$ & $26(19-32)$ & $23(36-59)$ & $20(60-80)$ \\
\hline Memories & 63 & $21 / 42$ & $24(19-32)$ & $22(36-59)$ & $17(60-70)$ \\
\hline Future intentions & 63 & $21 / 42$ & $24(19-32)$ & $22(36-59)$ & $17(60-70)$ \\
\hline \multicolumn{6}{|l|}{ Cognitive abilities } \\
\hline Episodic memory & & & & & \\
\hline Autobiographic (events fluency) & 53 & $16 / 37$ & $13(19-32)$ & $22(36-59)$ & $18(60-70)$ \\
\hline Verbal (ESR) & 57 & $16 / 41$ & $14(19-32)$ & $22(36-59)$ & $21(60-80)$ \\
\hline Visual (aBEM-144) & 57 & $16 / 41$ & $14(19-32)$ & $22(36-59)$ & $21(60-80)$ \\
\hline Semantic memory & & & & & \\
\hline Autobiographic (names fluency) & 55 & $16 / 39$ & $14(19-32)$ & $22(36-59)$ & $19(60-70)$ \\
\hline
\end{tabular}




\begin{tabular}{|c|c|c|c|c|c|}
\hline Verbal (category fluency) & 57 & $16 / 41$ & $14(19-32)$ & $22(36-59)$ & $21(60-80)$ \\
\hline Daydreaming & 55 & $16 / 39$ & $14(19-32)$ & $22(36-59)$ & $19(60-70)$ \\
\hline \multicolumn{6}{|l|}{ Self-related process } \\
\hline Self certainty (SQR) & 55 & $16 / 39$ & $14(19-32)$ & $22(36-59)$ & $19(60-70)$ \\
\hline \multicolumn{6}{|l|}{ Mental imagery } \\
\hline Generation of pictures (PIB) & 55 & $16 / 39$ & $14(19-32)$ & $22(36-59)$ & $19(60-70)$ \\
\hline \multicolumn{6}{|l|}{ Executive functions } \\
\hline Shifting (TMT) & 56 & $15 / 41$ & $14(19-32)$ & $22(36-59)$ & $20(60-80)$ \\
\hline
\end{tabular}


Table ST2: Results of the One Sample t-test on individual DMN z-maps in SPM5. Peak coordinates are given at $\mathrm{p} F W E=0.05, \mathrm{k}>300$.

\begin{tabular}{|c|c|c|c|c|c|c|c|}
\hline \multicolumn{3}{|c|}{ MNI coordinates } & \multirow[b]{2}{*}{$k$} & \multirow[b]{2}{*}{$T$} & \multicolumn{2}{|c|}{ Cluster level } & \multirow[t]{2}{*}{ Labeling } \\
\hline$x$ & $y$ & $z$ & & & $p F D R$ & $p$ uncorrected & \\
\hline 2 & -52 & 16 & 8069 & 35.22 & $9.8 \times 10^{-54}$ & $5.44 \times 10^{-55}$ & R Retrosplenial/Posterior Cingulate \\
\hline 0 & -54 & 30 & - & 28.98 & - & - & Precuneus/ Posterior Cingulate \\
\hline 26 & -18 & -18 & - & 18.86 & - & - & L Anterior Hippocampus \\
\hline 48 & -64 & 30 & 2011 & 20.17 & $1.45 \times 10^{-21}$ & $3.23 \times 10^{-22}$ & R Angular \\
\hline-46 & -68 & 30 & 2138 & 19.22 & $2.47 \times 10^{-22}$ & $4.11 \times 10^{-23}$ & L Angular \\
\hline-4 & 56 & -6 & 3617 & 18.83 & $1.48 \times 10^{-31}$ & $1.65 \times 10^{-32}$ & L Orbitofrontal/VentroMedial \\
\hline 4 & 62 & -6 & - & 18.80 & - & - & Prefrontal \\
\hline \multirow[t]{2}{*}{2} & 42 & -14 & - & 18.72 & - & - & $R$ Orbitofrontal \\
\hline & & & & & & & R Rectus Gyrus \\
\hline 24 & 32 & 52 & 628 & 15.43 & $2.89 \times 10^{-10}$ & $1.28 \times 10^{-10}$ & R Medial Frontal \\
\hline-62 & -14 & -14 & 936 & 15.31 & $3.72 \times 10^{-13}$ & $1.24 \times 10^{-13}$ & L Middle Temporal \\
\hline-64 & -42 & -12 & - & 6.50 & - & - & L Inferior Temporal \\
\hline 64 & -6 & -18 & 661 & 13.43 & $1.49 \times 10^{-10}$ & $5.82 \times 10^{-11}$ & R Middle Temporal \\
\hline-26 & 26 & 54 & 1062 & 13.25 & $3.27 \times 10^{-14}$ & $9.11 \times 10^{-15}$ & L Superior Frontal \\
\hline
\end{tabular}

$\mathrm{L}=$ left $; \mathrm{R}=$ right 
Table ST3: Summary of the sample size and mean performances $( \pm$ SD) for the InExQ questionnaire, according to the group

\begin{tabular}{|c|c|c|c|c|}
\hline & \multirow[b]{2}{*}{$\mathrm{n}$} & \multicolumn{3}{|c|}{ Mean group score (SD) } \\
\hline & & Young & Middle-aged & Aged \\
\hline \multicolumn{5}{|l|}{ Relative scores } \\
\hline$\%$ time thinking & 69 & $65.2(31.2)$ & $56.7(31.4)$ & $67.1(31.2)$ \\
\hline$\%$ visual thoughts & 69 & $57.8(31)$ & $61.9(31.1)$ & $67.4(33.1)$ \\
\hline$\%$ inner speech & 59 & $75.2(28.6)$ & $76.6(25.2)$ & $86.5(16)$ \\
\hline$\%$ future intentions & 66 & $66.7(27.2)$ & $70.3(36.2)$ & $52.7(37)$ \\
\hline$\%$ emotional thoughts & 69 & $43.6(34.3)$ & $43.7(36.4)$ & $50(36.1)$ \\
\hline$\%$ self-based thoughts & 68 & $86.9(16.7)$ & $72.3(36)$ & $87.1(17.4)$ \\
\hline \multicolumn{5}{|l|}{ Numbers } \\
\hline Total amount of thoughts & 69 & $7.17(4.9)$ & $5.3(3.3)$ & $5.4(3.5)$ \\
\hline Memories & 63 & $3.2(2.9)$ & $2.1(3)$ & $3.4(3)$ \\
\hline Future intentions & 63 & $3.7(2.7)$ & $2.8(2.2)$ & $2.6(2.6)$ \\
\hline
\end{tabular}


Table ST4: Summary of the sample size and mean scores ( \pm SD) for the cognitive ability tests, according to the group

\begin{tabular}{|c|c|c|c|c|}
\hline & \multirow[b]{2}{*}{$\mathrm{n}$} & \multicolumn{3}{|c|}{ Mean group score (SD) } \\
\hline & & Young & Middle-aged & Aged \\
\hline \multicolumn{5}{|l|}{ Episodic memory } \\
\hline Autobiographic (events fluency) & 53 & $9.5(4.8)$ & $6.20(3.1)$ & $5.2(4.5)$ \\
\hline Verbal (ESR) & 57 & $17.1(3.6)$ & $16.1(2.5)$ & $14.9(3.4)$ \\
\hline Visual (aBEM-144) & 57 & $20.6(5.3)$ & $18.4(4.3)$ & $15.6(4.2)$ \\
\hline \multicolumn{5}{|l|}{ Semantic memory } \\
\hline Autobiographic (names fluency) & 55 & $25.7(6.1)$ & $20.8(7.4)$ & $17(6.4)$ \\
\hline Verbal (category fluency) & 57 & $34.8(7.9)$ & $33(9)$ & $36.6(9.2)$ \\
\hline Daydreaming & 55 & $40.6(6.9)$ & $36.7(7.4)$ & $36.8(8.4)$ \\
\hline \multicolumn{5}{|l|}{ Self-related process } \\
\hline Self certainty (SQR) & 55 & $40.4(12.6)$ & $46.3(23.5)$ & $45.2(20.1)$ \\
\hline \multicolumn{5}{|l|}{ Mental imagery } \\
\hline Generation of pictures (PIB) & 55 & $26.2(2.04)$ & $26.6(1.9)$ & $27.4(2)$ \\
\hline \multicolumn{5}{|l|}{ Executive functioning } \\
\hline Shifting (TMT-time) & 56 & $24.1(8.6)$ & $34.2(15.3)$ & $49.1(24.4)$ \\
\hline
\end{tabular}




\section{3- Supplementary Material S3: Methodological considerations}

Different methodological factors have been tested to evaluate their influence on the main findings of the present study and select the optimal options. As the findings were similar for the three seeds referred to in the main manuscript (right PCC, right angular cortex, left vmPFC), the results are only presented for one of the seed in what follows, i.e. the right PCC.

\subsection{Choice of the seed: sphere versus cluster-based}

We first tested how the choice of the seed would influence our findings regarding the effects of age on the DMN. For this purpose, two seeds were used: 1) the spherical seed as described in the core manuscript (in yellow); 2) a cluster-based seed obtained from the One-sample ttest conducted on the DMN z-maps (in red).

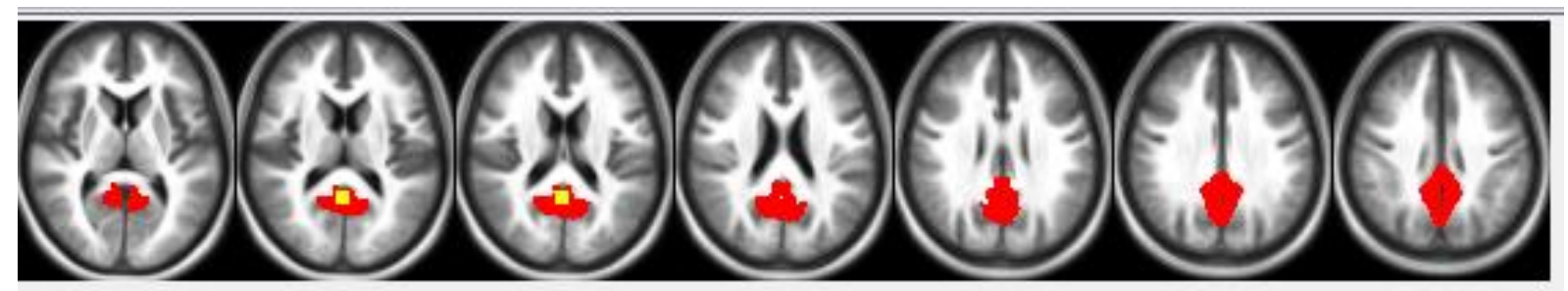

The following glass brains correspond to the negative linear correlation between age and the right PCC connectivity (controlling for gender and years of education, using the DMN explicit mask), at $\mathrm{p}$ FWE $<0.05, \mathrm{k}>30$ and using a. the spherical seed as reported in the manuscript versus b. the cluster-based seed.

a.

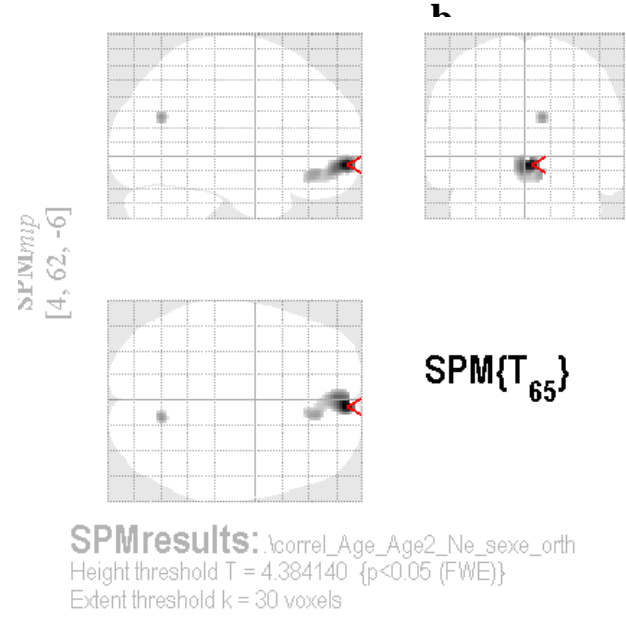

h.

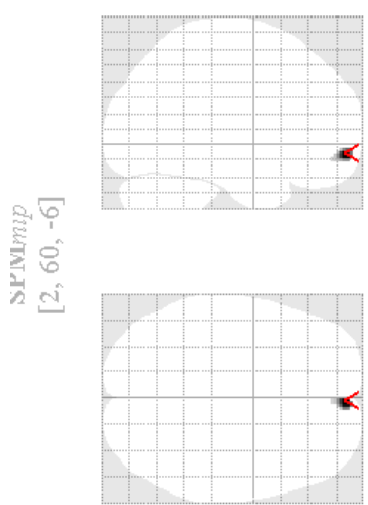

SPMresults: Extent threshold $k=30$ vorels $\{\mathrm{p}<0.05$ (FWE)

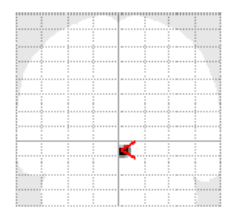

$\operatorname{SPM}\left\{T_{65}\right\}$ 
Conclusion on the choice of the seed: Despite significant difference in the size of the two seeds, the results were highly comparable.

\subsection{Choice of the statistical analysis: regression with age versus group comparisons.}

To investigate the effect of the statistical approach used to assess age-related effects on DMN connectivity, we compared the results observed using the 'Multiple regression' versus 'ANCOVA' routines in SPM5 - both of them corrected for years of education and gender, and using the DMN explicit mask. Among the 70 participants aged 19 to 80 years, 26 were

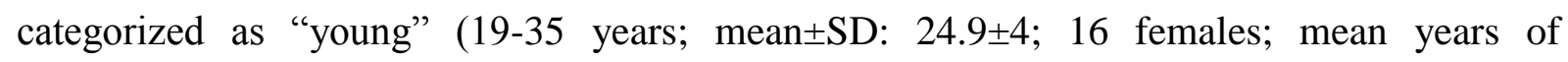
education: $15.2 \pm 3.1$ ), 23 as the middle-aged (36-59 years; mean \pm SD: $45.3 \pm 7.6$; 16 females; mean years of education: $12.7 \pm 3.2)$ and 21 as aged (60-80 years; mean \pm SD: $65.8 \pm 4.8 ; 17$ females; mean years of education: $11.8 \pm 3.3$ ). The glass brains below correspond to a. the linear negative correlation as reported in the manuscript, b. the contrast young > aged and $\mathbf{c}$. the contrast middle-aged $>$ aged $(\mathrm{p} \mathrm{FWE}<0.05 ; \mathrm{k}>30)$ :

a.

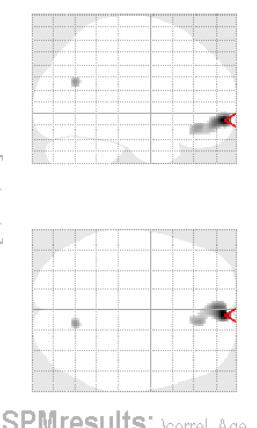

SPMresults:

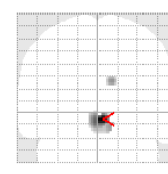

$\operatorname{SPM}\left\{\mathrm{T}_{65}\right\}$ b.

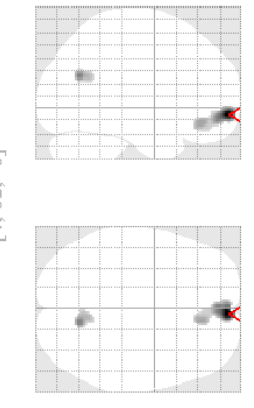

SPMresults:

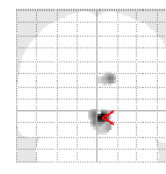

$\operatorname{SPM}\left\{\mathrm{T}_{65}\right\}$ c.

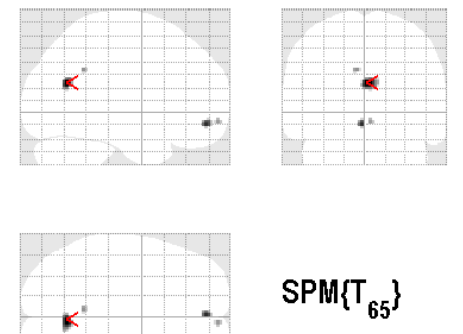

Conclusion on the choice of the statistical test: Assessing the correlation with age or the inter-groups differences provided consistent results. Furthermore, the results of the ANCOVA confirmed the linear effect of age on PCC connectivity as they showed that, especially in the ventro-medial prefrontal cortex, PCC connectivity in middle-aged is intermediate between young and aged. 


\subsection{Influence of gray matter atrophy on age effects: BPM analyses}

In order to assess the influence of gray matter atrophy on the results, we used the voxel-wise regression routine available in the robust Biological Parametric Mapping toolbox (Yang et al., 2011). This routine allows to enter an imaging dependent variable, while regressing out the effect of several imaging and non-imaging regressors in a voxel-by-voxel analysis. Briefly, the 70 individual preprocessed maps of the right PCC connectivity were entered as the dependent variable. The corresponding smoothed modulated-normalized segmented gray matter maps, as well as orthogonalized age and $\operatorname{age}^{2}$, years of education and gender were entered in the toolbox as regressors. Finally, the DMN explicit mask was selected. The following glass brains (a. negative $\mathrm{T}$ and $\mathbf{b}$. $\mathrm{F}$ contrasts) were obtained when assessing the effect of age at $\mathrm{p}$ uncorrected $<.001, \mathrm{k}>30$. Note that there was no significant finding for the positive T-test or for the effect of age $^{2}$ even when using a more permissive statistical threshold (uncorrected $\mathrm{p}<0.01$ ).

a.

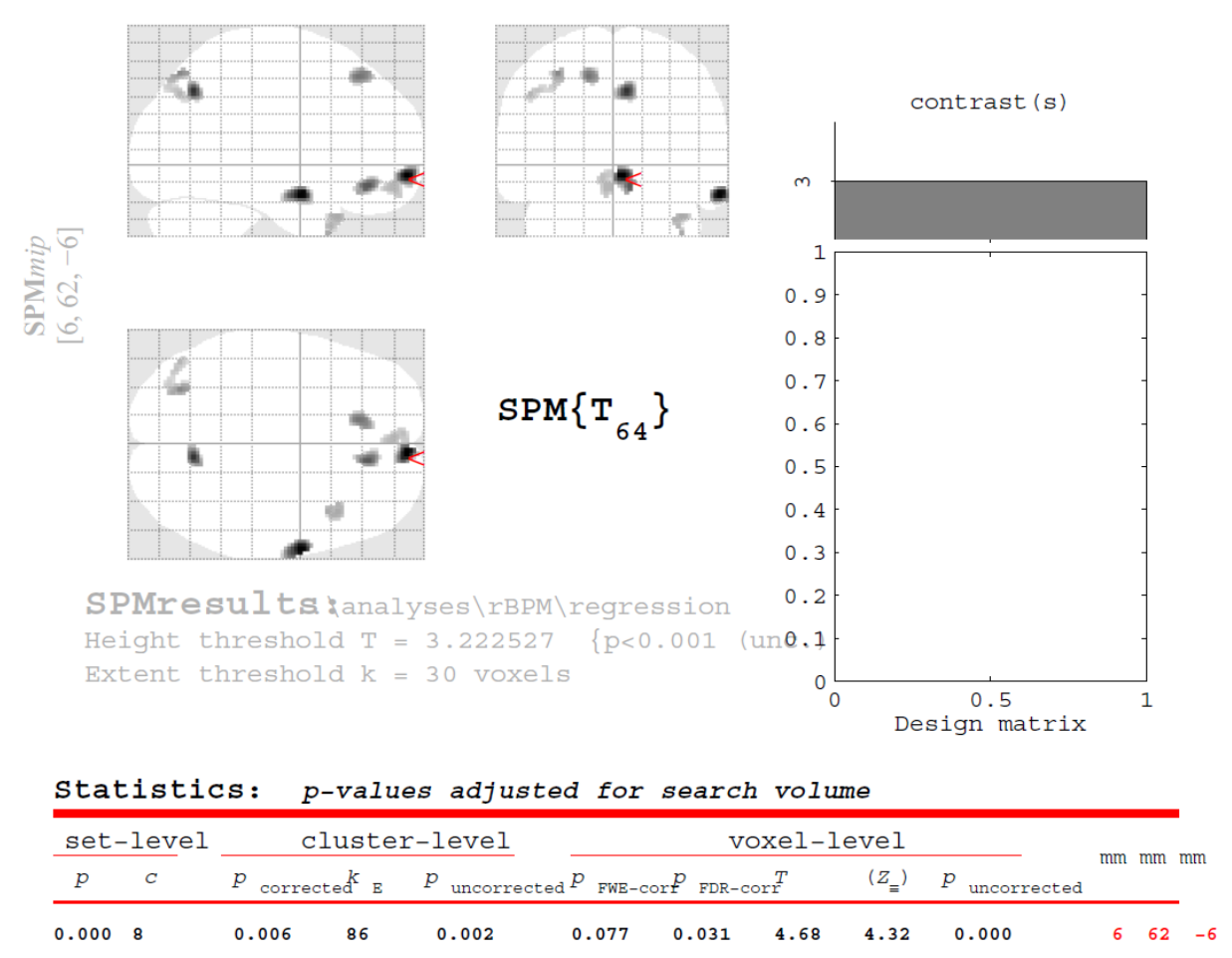


b.

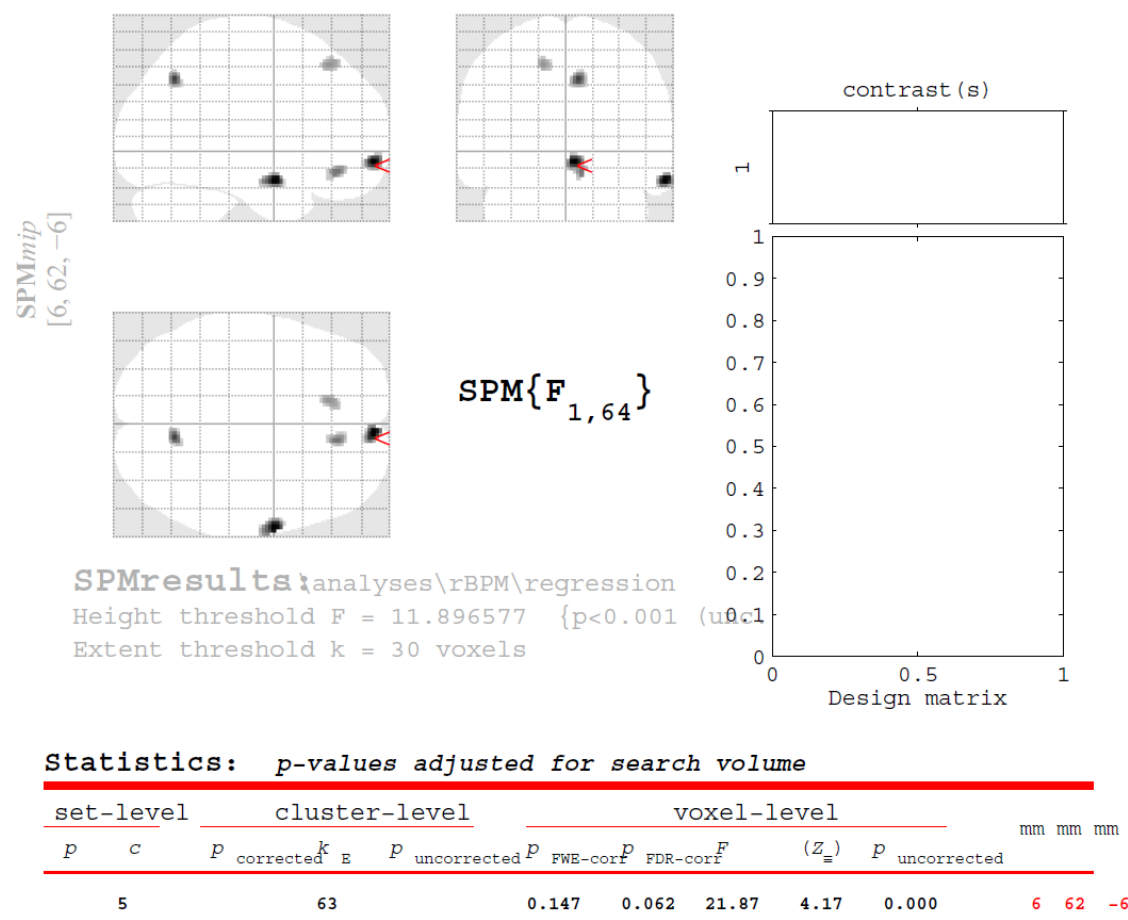

Conclusion on the influence of gray matter atrophy: The regional gray matter atrophy accounted for a relatively small part of variability in the observed anterior-posterior disruption. Although the statistical thresholds were lower, both $\mathrm{T}$ negative and $\mathrm{F}$ regression contrasts obtained when taking into account the individual gray matter maps pointed to a predominant age-related effect on the PCC connectivity in the right vmPFC.

\section{References}

Bourlon, C., Oliviero, B., Wattiez, N., Pouget, P., Bartolomeo, P., 2011. Visual mental imagery: what the head's eye tells the mind's eye. Brain Res. 1367, 287-297.

Buckner, R.L., Andrews-Hanna, J.R., Schacter, D.L., 2008. The brain's default network: anatomy, function, and relevance to disease. Ann. N. Y. Acad. Sci. 1124, 1-38.

Kosslyn, S.M., 1994. Image and brain, MIT Press, Cambridge.

Yang, X., Beason-Held, L., Resnick, S.M. Landman, B.A., 2011. Biological parametric mapping with robust and non-parametric statistics. Neuroimage 57, 423-430. 